\title{
Parâmetros de controle de estilos fluviais na bacia hidrográfica do alto curso do rio Piranhas, semiárido paraibano
}

\author{
Parameters for the control of river styles in the hydrographic basin of the high course of river \\ Piranhas, semi-arid of Paraiba
}

\author{
Jeferson Mauricio Rodrigues \\ Mestrando em Geografia, Universidade Federal da Paraíba (UFPB), Brasil \\ Jefersonmrgeo@gmail.com \\ Jonas Otaviano Praça de Souza \\ Doutor em Geografia, Universidade Federal de Pernambuco (UFPE) \\ Professor Adjunto da Universidade Federal da Paraíba (UFPB), Brasil \\ Jonasgeoufpe@yahoo.com.br
}

\begin{abstract}
Resumo
Este estudo ocorreu em uma bacia de drenagem no semiárido paraibano e tem como objetivo analisar a relação entre os parâmetros de controle identificados no perfil longitudinal do alto curso do rio Piranhas com seus respectivos estilos fluviais. Nessa perspectiva, foi necessário identificar e caracterizar os 6 estilos fluviais existentes no alto curso do rio Piranhas para posteriormente correlaciona-los com a variação de anomalias de declividade e variação da energia de fluxo do rio Piranhas, tendo em vista que estas variáveis foram plotadas ao perfil longitudinal e são tidas como parâmetros condicionantes de processos geomorfológicos em sistemas fluviais. Desta maneira, observou-se que as anomalias de $1^{\mathrm{a}}$ ordem estão intimamente associadas aos altos índices de stream power - SPI (energia de fluxo), o que condiciona processos erosivos nos estilos confinados. Diferentemente, nos estilos não confinados ocorre a predominância de anomalias de $2^{\mathrm{a}}$ ordem e índices stream power menores, condicionando processos de transporte e deposição.
\end{abstract}

Palavras-chave: Estilos Fluviais; Anomalias; Energia de fluxo.

\begin{abstract}
This study occurred in a drainage basin in the semi-arid region of Paraíba and aimed to analyze the relationship between the controls parameter used in the longitudinal profile of the upper course of the Piranhas River with their river styles. In this perspective, it was necessary to identify and characterize the six river styles existing in the upper Piranhas River to correlate them later with the variation of anomalies of slope and variation of the stream power of the Piranhas River, considering that these areas were planned longitudinal profile and are measured as conditioning factors for geomorphological processes in river systems. In this way, it can be considered that the anomalies of the $1^{a}$ order are strictly related to the high levels of stream power, or that they condition erosive processes in confined styles. Differently in non-confined styles, there is a predominance of $2^{\mathrm{a}}$ order anomalies and lower Stream Power indexes (Stream Power), conditioning transport and deposition processes.
\end{abstract}

Keywords: River styles; Anomalies; Stream Power. 


\section{INTRODUÇÃO}

O sistema fluvial é um sistema não isolado aberto e funcional, onde o output de energia de um sistema climático se torna o input de energia do sistema bacia hidrográfica e consequentemente fluvial (SOUZA, 2013). É importante salientar que nenhum dos processos fluviais - erosão, transporte e sedimentação - funcionam de forma excludente, ou em pontos isolados no sistema, mas, podem ocorrer simultaneamente numa mesma área, com a predominância de um desses processos, gerando assim, suas zonas (SHUMM, 1977).

Em ambientes secos há a predominância de canais efêmeros e intermitentes. O canal intermitente só apresenta fluxo durante o período chuvoso, passando parte do ano seco e a sua principal característica singular está nas forças que organizam seu ecossistema, localizados principalmente nas áreas de exceção do semiárido, que contribui muito para a diversidade biológica e paisagística da região (MALTCHICK, 1999). Já os canais efêmeros apresentam vazões de curta duração que varia de horas a poucos dias durante ou logo após o evento de chuva, ocasionando uma descontinuidade. Outro fator que condiciona este comportamento são as tempestades que cobrem apenas uma parte da bacia, onde o transporte de fluxo sofre uma redução à jusante, com perdas por infiltração e evaporação (SUTFIN et al., 2014). Tendo em vista que o período de escassez de água no canal é frequente e periódico, pode-se afirmar que tal fenômeno é seu funcionamento normal, pois qualquer nível de vazão atua como uma cheia que realiza o trabalho mecânico (SOUZA, 2015). Para ambientes semiáridos tropicais, como o caso do semiárido brasileiro, há uma defasagem nos estudos sobre dinâmica fluvial, e ao mesmo tempo é importante o desenvolvimento de técnicas e metodologias aplicáveis a esses ambientes (LIMA et al., 2019).

Devido à complexidade do sistema fluvial, há necessidade de ordenamento dessa variabilidade tendo em vista a obtenção de confiança na apresentação de resultados de pesquisa ou gerenciamento de sistemas funcionalmente semelhantes. Apesar das classificações para sistemas lóticos terem utilizado como base as variáveis físicas e biológicas, ainda é um desafio fazer a integração bem-sucedida dessas variáveis relacionados em uma estrutura organizada com processos que variam no espaço e no tempo (THOMSON et al., 2004).

A classificação é ferramenta essencial para pesquisadores que tem por finalidade agrupar locais funcionalmente semelhantes ou identificar habitats únicos ou ameaçados. Um esquema de classificação de rios baseados em processos que integre os aspectos físicos e biológicos de forma e função lóticas melhoraria os processos de conservação e restauração, permitindo comparações mais significativas entre os locais e melhorar a compreensão funcional dos ecossistemas fluviais (THOMSON et al., 2004).

A estrutura de estilos de rio é um procedimento hierárquico para gerenciamento de rios, na qual os processos de alcance de escala são explicados dentro de um contexto de unidades de 
paisagem, que por sua vez, controlam a variedade de estilos formados ao longo de nossos rios. Os controles primários para induzir a condição e comportamento do rio estão nos tipos de vale, unidades geomórficas e textura de material de leito (THOMSON et al., 2004).

É possível identificar os controles que ocorrem longitudinalmente, ou seja, o perfil longitudinal pode indicar a relação do relevo com as características comportamentais de diferentes estilos de rio em uma mesma bacia hidrográfica (BRIERLEY e FRIYRS, 2005). Nesse sentido, o perfil longitudinal de um rio representa suas variações topográficas no que tange à altimetria e declividade de sua nascente até a foz através de um plano cartesiano. De modo geral, o perfil longitudinal de um rio está intimamente ligado ao relevo, representando o rio através de um eixo de ordenadas que representa as altitudes e outro eixo de abscissas que representa a extensão (SILVA et al., 2016). O perfil Longitudinal apresenta tipicamente uma curva parabólica côncava e declividades mais acentuadas em direção à nascente e declividades menores próximo à foz (CHRISTOFOLETTI, 1981).

É importante salientar que perfis que estejam dentro da perspectiva da concavidade exponencial apresentam equilíbrio no balanço de sedimentos, tendo em vista a importância da exportação de material sedimentar e energia (SCHUMM, 1977). No entanto, é praticamente impossível de observar na natureza um perfil exatamente côncavo, tendo em vista as irregularidades naturais e declives acentuados gerados por fatores geomorfológicos (LIMA, 2013). Nesse sentido, entende-se como anomalia de drenagem as rupturas de declive que indicam variações abruptas de altimetria do terreno em um curto espaço de extensão.

As anomalias de drenagem representadas como rupturas de declive, indicam desajustes que podem ser classificados como anomalias de $1^{\mathrm{a}}$ Ordem ou $2^{\mathrm{a}}$ Ordem. Assim, as anomalias de $1^{\mathrm{a}}$ Ordem indicam anomalias mais acentuados e os de $2^{\text {a }}$ Ordem apresenta suavidade maior que a de $1^{\text {a }}$ Ordem (SILVA et al., 2016). Estas anomalias comprometem ou condicionam os processos geomorfológicos atuantes em um canal fluvial, pois a velocidade do fluxo e a carga detrítica transportada são condicionadas pelo declive da superfície (CHRISTOFOLETTI, 1980), ou seja, estas anomalias provocam alterações no transporte e na fisiografia de um canal em trechos à montante e à jusante da zona deformada (ZANCOPÉ; PEREZ FILHO; CARPI JUNIOR, 2009).

Outro indicativo associado ao perfil longitudinal é o índice de energia de fluxo (Stream Power Index - SPI), é um indicativo de potêncial de vazão de energia de fluxo em determinado trecho de rio em uma bacia hidrográfica, e construído a partir de atributos primários e secundários, como declividade, MDE (Modelo Digital de Elevação), fluxo acumulado (Flow Accumulation) e índice de acumulação de fluxo (TWI) (DANIELSON, T. 2013). De acordo com Wilson e Lorang (2000), o SPI é um indicativo de processo geomorfológico atuante em uma determinada área de 
captação, tendo em vista que a mensuração de erosão a partir da energia de fluxo da água em uma bacia está associada a um perfil convexo e de deposição onde o perfil apresenta-se côncavo.

O objetivo da pesquisa aqui relatada é definir os estilos fluviais e identificar os parâmetros de controle da distribuição da tipologia de rios na bacia hidrográfica do Alto Curso do Rio Piranhas no semiárido da Paraíba.

\section{METODOLOGIA}

\subsection{Caracterização da Área}

Este trabalho tem como área de pesquisa a bacia do Alto Curso do Rio Piranhas localizada no Sertão paraibano, ocupando uma área de 35 Municípios que dentre os principais estão: Cajazeiras, Souza e Pombal. O ponto de exutório da bacia está na confluência com o Rio Piancó e o canal principal possui 174,22 km de extensão, sendo que o motivo pelo qual foi escolhida esta área para estudo é que ela mantém características de vazão naturais, por não sofrer influência da Barragem Coremas - Mãe D’água (localizada no Rio Piancó - Afluente do Piranhas), que pereniza artificialmente o Médio e Baixo Curso do Rio Piranhas durante o ano inteiro após a confluência com o rio Piancó e altera suas condições/características naturais de vazão (intermitente) (Figura 1).

A área da bacia do Alto Curso do Rio Piranhas é de aproximadamente $6010,73 \mathrm{~km}^{2}$, sobre a Depressão Sertaneja, tendo características físicas semelhantes a boa parte do semiárido nordestino. A Depressão Sertaneja é organizada em torno do Planalto da Borborema, e é resultado de morfologia herdada de processos morfoestruturais, onde nessas zonas aplainadas os processos denudacionais superam os agradacionais, formando vastas superfícies erosivas, e consequentemente, pedimentos entre o sopé das encostas e os ambientes fluviais, onde a coalescência desses pedimentos formam os pediplanos - processos frequentes da chamada Depressão Sertaneja (MAIA et al., 2010). 


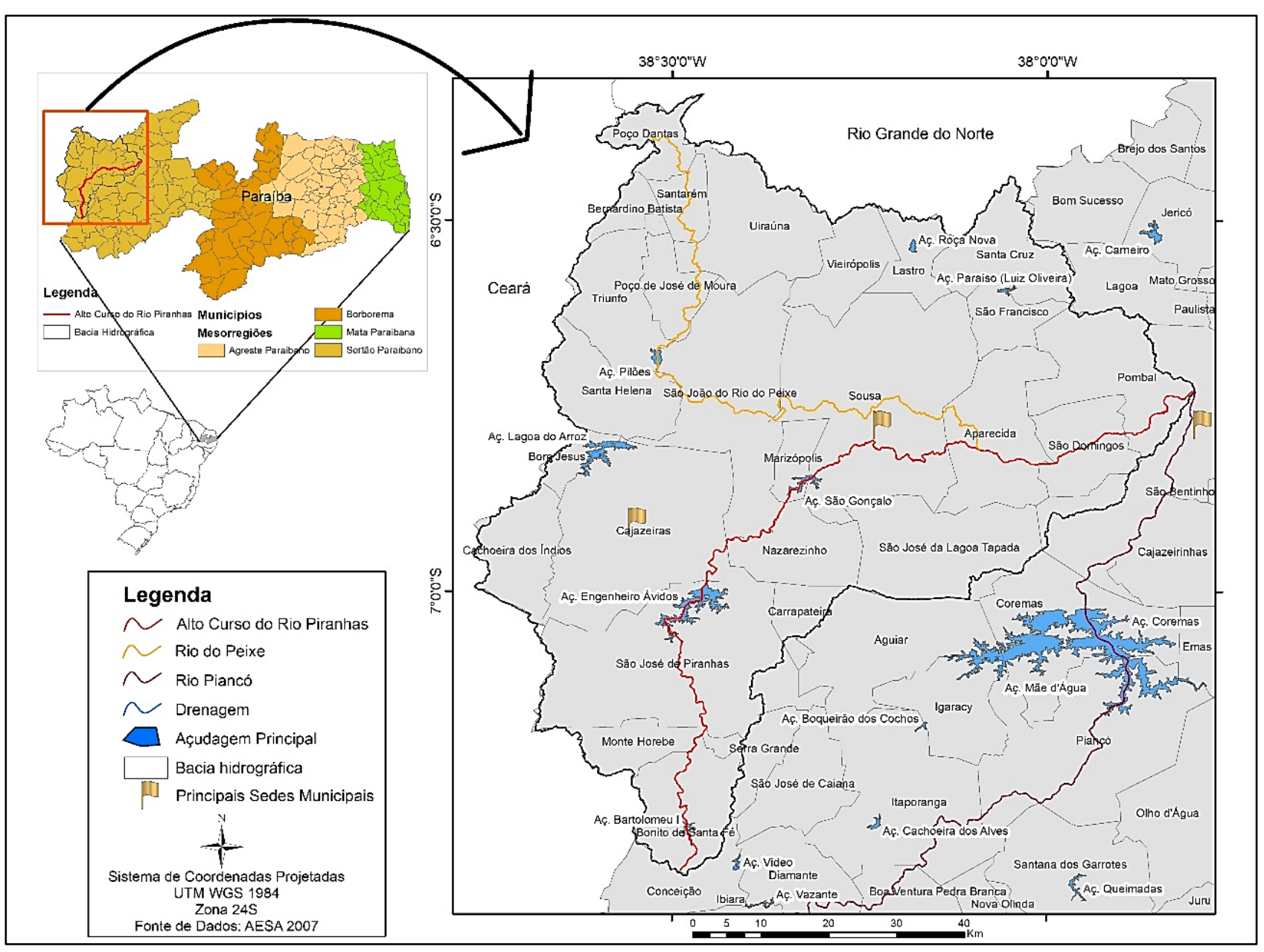

Figura 1 - Mapa de localização da bacia do alto curso do rio Piranhas.

Fonte: Autoral (2020).

Todavia, por mais que a Depressão Sertaneja esteja circundando o Planalto da Borborema, deve-se levar em consideração que ambas fazem parte da Província Estrutural Borborema que compreende grande parte tectônica e estrutural do Nordeste brasileiro, podendo ser entendida como uma faixa colisional envolvendo processos de amalgamação e acreção de microplacas e terrenos consolidados ao final do evento brasiliano no terciário superior, ou seja, um cinturão orogênico meso/neoproterozóico que se estende por grande parte do Nordeste (CAMPELO, 1999) e com a existência de zonas de cisalhamento indica a grande mobilidade que a mesma foi submetida, o que possibilitou a compreensão da Província Borborema a partir de uma subdivisão em Sub-províncias que foram delineadas com base em sua evolução tectônica e estratigráfica.

A bacia hidrográfica do Alto Curso do Rio Piranhas está compreendida sobre parte das seguintes Sub-províncias: Zona Transversal, Domínio Rio Grande do Norte, Cobertura Cenozóica Insdiscriminada e Bacias Sedimentares Interiores da Borborema (Figura 2). 


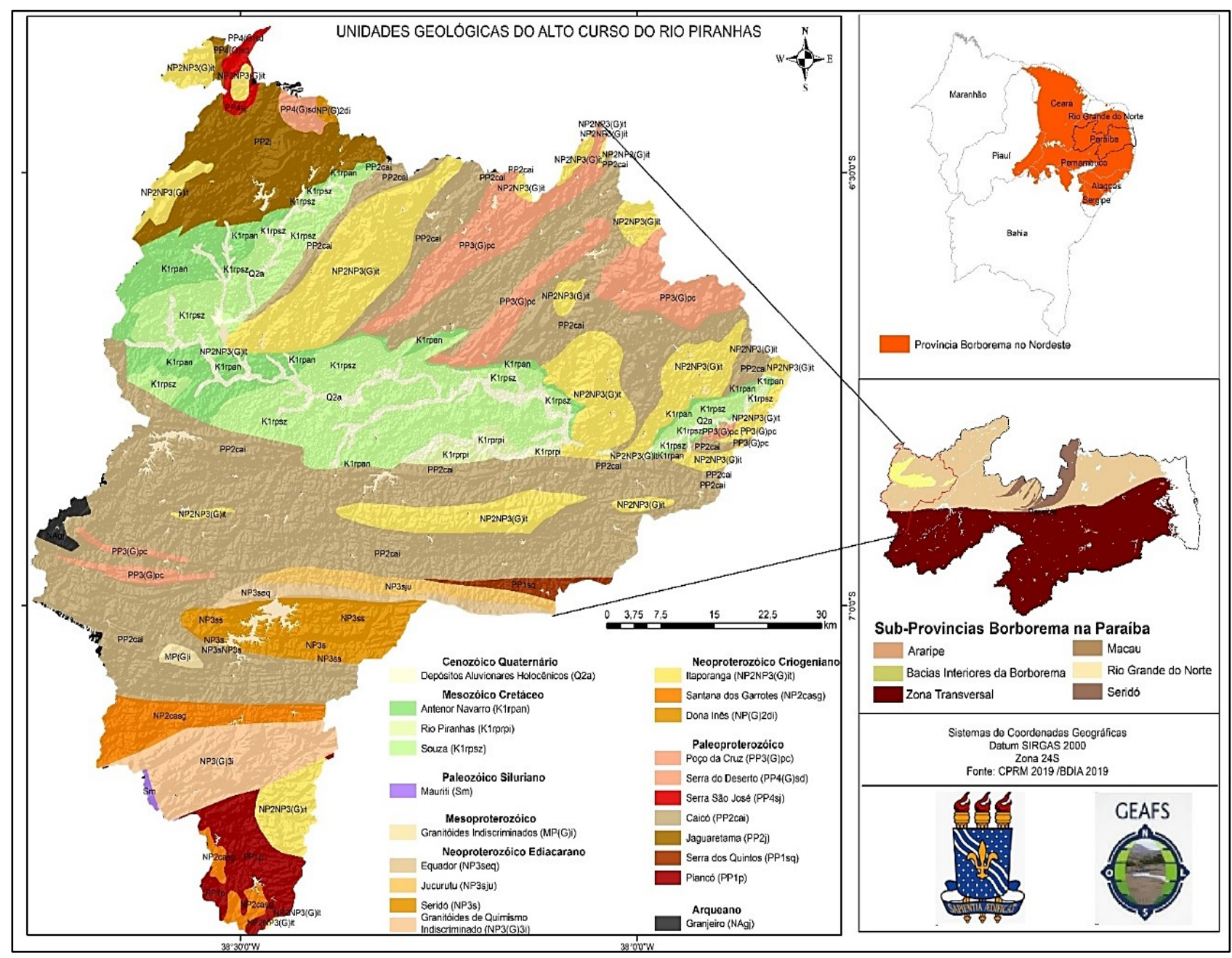

Figura 2 - Geologia da bacia do alto curso do rio Piranhas.

Fonte: Autoral (2020).

As litologias da bacia do alto curso do rio Piranhas variam de cristalinas, metamórficas e sedimentares, tendo em vista que o terço inferior é onde o curso do rio escoa sobre rochas sedimentares, enquanto o terço médio e superior a predominância é de rochas cristalinas maciças.

\subsection{Procedimentos Metodológicos}

Para definir e mapear os estilos de rio na bacia hidrográfica foi necessário avaliar três variáveis dos sistemas fluviais, conforme proposto por Brierley e Fryirs (2005), que foram: configuração de vale, unidades geomórficas e textura de material de leito (Tabela 1). 
Tabela 1 - Variáveis de análise para definição de estilos fluviais. Fonte: Brierley e Fryirs, 2005.

\begin{tabular}{cccc}
\hline CONFIGURAÇÃO DE & CONFIGURAÇÃO DE VALE & \multirow{2}{*}{ CONFIGURAÇÃO DE VALE NÃO - CONFINADO } \\
VALE CONFINADO & PARCIALMENTE CONFINADO & $(<10 \%$ DE CONFINAMENTO DE MARGEM) \\
\hline (>90\% DE MARGEM & (ENTRE 10 E 90\% DE & & \\
CONFINADA) & CONFINAMENTO DE MARGEM) & PRESENÇA DE CANAIS \\
PRESENÇA/AUSÊNCIA & GRAU DE CONFINAMENTO & AUSÊNCIA OU CANAIS & DESCONTINUS \\
DE VÁRZEAS & LATERAL E CONFIGURAÇÃO DO & DESCONTINOS & \\
& VALE (RETO - IRREGULAR - & & FORMA EM PLANTA \\
SINUOSO) & UNIDADES & UNIDADES \\
UNIDADES & FORMA EM PLANTA DO CANAL & GEOMÓRFICAS & GEOMÓRFICAS \\
TEXTURA DE MATERIAL & UNIDADES GEOMÓRFICAS & TEXTURA DE MATERIAL & DE SUPERFÍCIE \\
DE LEITO & TEXTURA DE MATERIAL DE & & TEXTURA DE MATERIAL \\
& LEITO & DO LEITO \\
\hline
\end{tabular}

\subsubsection{Configuração de Vale}

A configuração de vale é o ponto de entrada para definir o estilo de rio, e é definida pelo grau de confinamento do canal, expressa pela presença/ausência de várzeas ao longo dos cursos fluviais (BRIERLEY; FRYIRS, 2005). Assim, os canais podem ser confinados, parcialmente confinados e não confinados. Geralmente os canais confinados apresentam menos de $10 \%$ de planícies de inundação em ambas as margens do canal. Os parcialmente confinados apresentam entre $10 \%$ e $90 \%$ de planície de inundação em ambas as margens do canal, e dessa forma as planícies podem ser alternadas ou descontínuas ao longo do curso fluvial. Os não confinados apresentam menos de $10 \%$ de confinamento de margem, com planícies de inundação contínuas ao longo das margens e podem ter canais contínuos e canais descontínuos. Nessa perspectiva, para gerar informações sobre a largura do vale e representar topograficamente as unidades geomórficas de acordo com suas variações de altura no ambiente fluvial, foi utilizada estação total, onde os pontos de coleta foram de uma margem à outra.

\subsubsection{Unidades Geomórficas}

As unidades geomórficas são ferramenta chave para interpretar o caráter e comportamento do canal. É o principal parâmetro interpretativo na estrutura de estilos de rio. Os critérios utilizados são: número de canais, sinuosidade, barras e ilhas. Tendo em vista que este procedimento foi feito tanto em gabinete como em campo, é importante salientar que para identificar o número de canais, sinuosidade, barras e ilhas serão utilizadas imagens de satélite do Google Earth mais recentes que permitam visualizar a planta do canal, no momento em que será gerado o mapa de estilos de gabinete. Após a identificação das unidades geomórficas através de imagens de satélite, foi feito um mapeamento de distribuição das unidades nos trechos fluviais e um campo de coleta e confirmação tendo em vista a necessidade de delimitá-las. 


\subsubsection{Textura de Material de Leito}

Outro procedimento que foi realizado em campo é a identificação da textura de material de leito. Esta é determinada através da base de calibre dominante encontrado no leito fluvial. Assim, foram utilizados procedimentos de análise granulométrica em laboratório para definir o calibre do material sedimentar encontrado no leito dos sistemas fluviais. Desta maneira, são utilizadas 5 classes: Leito rochoso; Rocha (> $256 \mathrm{~mm})$; Cascalho $(2-256 \mathrm{~mm})$; Areia $(0,0625-2 \mathrm{~mm})$; Silte e Argila $(<0,0625 \mathrm{~mm})$.

Assim, após definir o mapa de estilos fluviais para a bacia do Alto Curso do Rio Piranhas, foram analisados os parâmetros que condicionam o comportamento fluvial dos estilos fluviais da bacia hidrográfica do Alto Curso do Rio Piranhas.

Posteriormente, foram analisadas as anomalias de declividade e stream power como variáveis de análise para definir parâmetros de controles fluviais conforme proposto por Brierley e Fryirs, 2005.

\subsubsection{Padrões de Controle}

Para identificar os controles foi necessário gerar um diagrama através da plotagem dos estilos nos perfis longitudinais para identificar as relações entre inclinação - descargas e faixas associadas de condição de energia do canal sobre o qual os estilos são observados, e com a geologia. Também foi utilizado para identificar se o canal atua em zona fonte, transporte ou deposição de sedimentos e onde ocorrem as rupturas de passagem de um estilo para outro.

Para isso, foi feito um mapa de anomalia através do índice de gradiente (HACK, 1973), que indicará onde ocorrem as rupturas de declive mais acentuadas na bacia hidrográfica e será gerado também o stream power que é um atributo topográfico composto. Este último é uma medida do poder erosivo da água corrente, com base no pressuposto de que a descarga é proporcional à área de captação específica. Geralmente prediz erosão líquida em áreas de perfil e convexidade tangencial (zonas de aceleração e convergência de fluxo) e deposição líquida em áreas de concavidade de perfil (zonas de velocidade de fluxo decrescente) (POURGHASEMI et al., 2013).

O primeiro passo para gerar o índice de gradiente para o canal principal completo do rio Piranhas, é que o perfil longitudinal deve apresentar valores aritméticos de altitude e extensão. Posteriormente, será necessário converter a extensão total do canal principal para escala logarítmica natural. Após a conversão será feito o seguinte cálculo:

$$
\text { Ktotal }=\frac{\Delta H}{\Delta \ln L}
$$


Onde Ktotal é o índice de gradiente do canal principal completo, $\Delta \mathrm{H}$ é a amplitude do canal principal, e $\Delta \operatorname{lnL}$ é o logaritmo natural da extensão do rio Piranhas completo.

Posteriormente, foi feita um seccionamento no canal principal com intervalo de distância de $2 \mathrm{~km}$, tendo em vista a necessidade de gerar o índice de gradiente por pontos do canal principal. Assim, foi aplicada a seguinte fórmula para este procedimento:

$$
\text { Ktrecho }=\frac{\Delta H}{\Delta l} * L
$$

Sendo que Ktrecho é o índice de gradiente do trecho, $\Delta \mathrm{H}$ é a amplitude do trecho, $\Delta \mathrm{l}$ é a distância entre o ponto mais alto e o mais baixo do trecho, e L é a extensão entre o ponto mais baixo do trecho e o ponto de cabeceira do canal principal como representado na Figura 3.

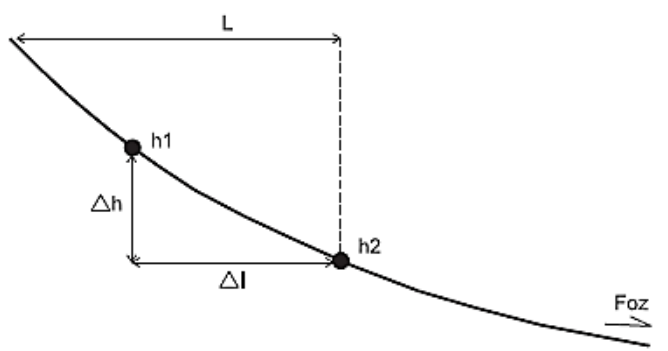

Figura 3 - Parâmetros utilizados no cálculo do índice de Gradiente de Hack (1973).

Fonte: Etchebehere (2000).

Após a geração do Índice de Gradiente de trecho (Ktrecho) e Canal principal completo (Ktotal), será possível gerar o índice de anomalia de inclinação através da seguinte equação:

$$
\text { Anomalia }=\frac{\text { Ktrecho }}{\text { Ktotal }}
$$

Sendo que Ktrecho é o índice de gradiente por trecho e Ktotal é o índice de gradiente do canal principal.

A razão gerada pela última fórmula é organizada em 3 parâmetros de anomalia, onde valores entre 0 e 2 correspondem a trechos equilibrados; entre 2 e 10 correspondem a anomalias de $2^{\text {a }}$ Ordem; e acima de 10 correspondem a anomalias de $1^{\text {a }}$ Ordem.

Para análise da energia de fluxo no canal, ou seja, o Stream Power Index (SPI), Tagil e Jenness (2008) afirmam que o SPI é utilizado para mensurar o poder de erosão da água em um terreno, onde áreas que possuem índices altos de Strem Power possuem ótimas condições para gerar erosão. Segundo os referidos autores, o Stream Power pode ser obtido através da seguinte equação:

$$
\text { Stream Power }=\text { Área de captação } * \text { Tan (declividade) }
$$


Sendo a área de captação de fluxo utilizada para a equação foi o TWI multiplicado pela tangente da declividade.

Através de uma tabela de controle de padrões à jusante e condição de contorno será feita uma comparação entre os estilos fluviais identificados e determinar seus parâmetros de controle que operam em cada estilo de rio. Os parâmetros avaliados foram: processo de zona, confinamento lateral, textura de material de leito, unidades geomórficas, anomalias e energia de fluxo.

\section{RESULTADOS E DISCUSSÕES}

Inicialmente, a definição de estilos fluviais foi realizada a partir de levantamentos de gabinete, no que tange à identificação de confinamento de vale, unidades geomórficas e textura de material de leito. Posteriormente, o trabalho de campo foi utilizado para coleta de dados sobre o caráter e comportamento do rio, tendo em vista a busca dos limites de cada estilo (BRIERLEY e FRYIRS, 2005). Assim, foi gerado o mapa de estilos fluviais da bacia do alto curso do rio Piranhas, através da análise de imagens de satélite do Google Earth, que permitiu a identificação das unidades geomórficas, e respectivamente do confinamento do vale. O campo permitiu a identificação da textura de material de leito e a confirmação dos dados levantados em laboratório (Figura 4).

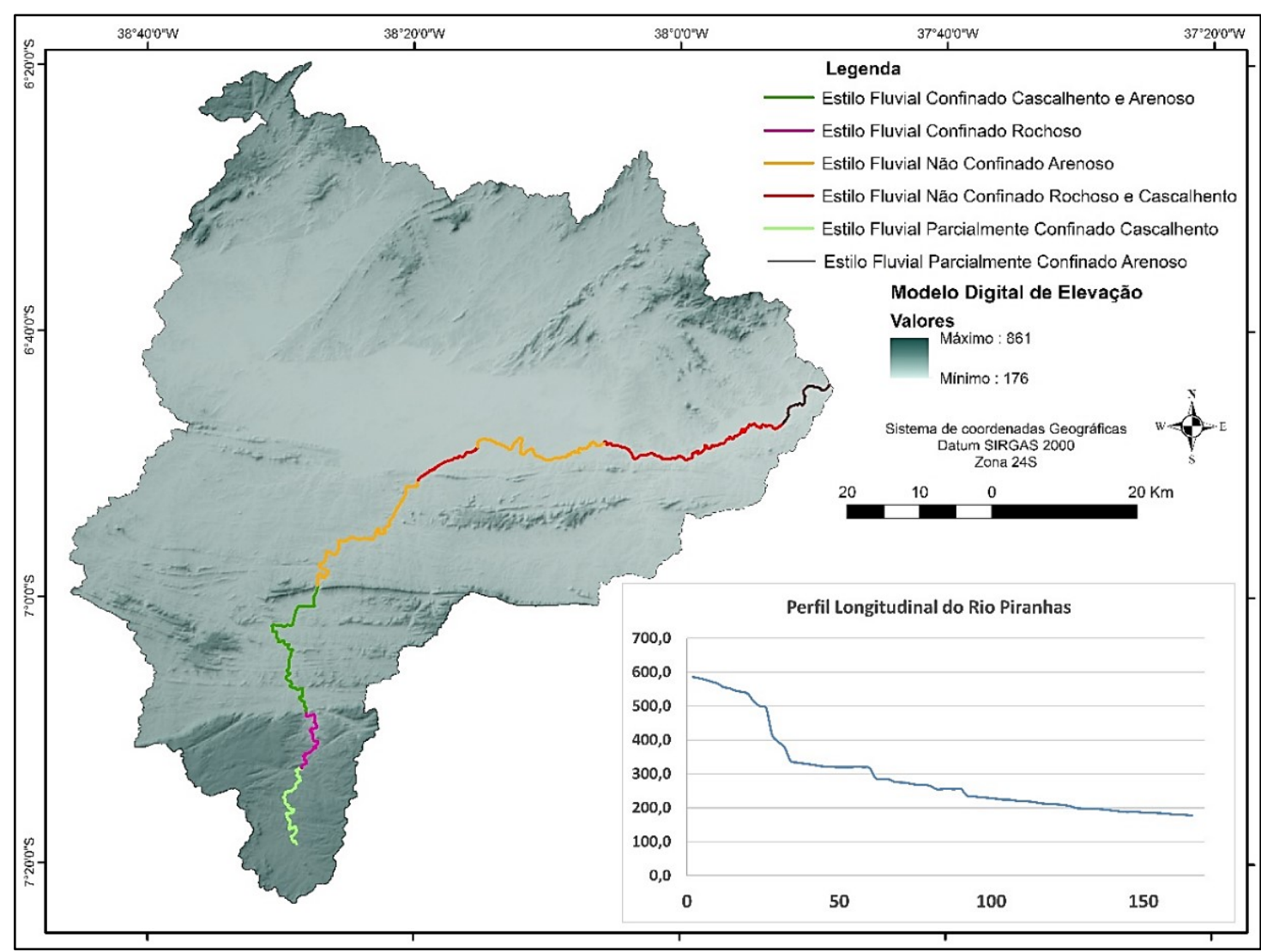

Figura 4 - Estilos Fluviais do Alto Curso do Rio Piranhas.

Fonte: Autoral (2020). 
Após a definição dos estilos fluviais, foi construída uma matriz de informações gerais dos estilos, o que permitiu descrever os atributos distintivos entre eles. A nomenclatura dos estilos foi definida tendo em vista sua morfologia e processos atuantes, ou seja, o caráter e comportamento do alcance fluvial. De modo geral, o limite entre um estilo e outro foi definido através de alterações nas unidades geomórficas, atributo chave da definição de estilos fluviais. Em última instância, o atributo selecionado para distinguir os estilos foi a textura de material de leito (Tabela 3).

Tabela 2 - Matriz de Estilos Fluviais do Alto Curso do Rio Piranhas.

\begin{tabular}{|c|c|c|c|c|c|c|}
\hline \multicolumn{7}{|c|}{ MATRIZ DE ESTILOS FLUVIAIS } \\
\hline \multicolumn{7}{|c|}{ Características fluviais } \\
\hline Estilo Fluvial & EFPCC & EFCR & EFCCA & EFNCA & EFNCRC & EFPCA \\
\hline $\begin{array}{c}\text { Configuração em } \\
\text { planta }\end{array}$ & Sinuoso & Sinuoso & Irregular & Irregular & Meandrante & Irregular \\
\hline \multirow[t]{2}{*}{ Configuração do vale } & $\begin{array}{l}\text { Parcialmente } \\
\text { confinado }\end{array}$ & Confinado & Confinado & $\begin{array}{l}\text { Não } \\
\text { confinado }\end{array}$ & Não confinado & $\begin{array}{l}\text { Parcialmente } \\
\text { confinado }\end{array}$ \\
\hline & Ilhas & $\begin{array}{l}\text { Soleiras } \\
\text { Rochosas }\end{array}$ & $\begin{array}{c}\text { Terraço margem } \\
\text { esquerda }\end{array}$ & $\begin{array}{l}\text { Planície nas } \\
\text { duas margens }\end{array}$ & Soleiras rochosas & Terraço \\
\hline \multirow[t]{2}{*}{ Unidades Geomórficas } & Barras & Matacões & $\begin{array}{l}\text { Afloramento } \\
\text { rochoso }\end{array}$ & Barras & $\begin{array}{l}\text { Planície nas duas } \\
\text { margens }\end{array}$ & Barra arenosa \\
\hline & $\begin{array}{l}\text { Planície de } \\
\text { inundação }\end{array}$ & Marmitas & & Ilhas & & $\begin{array}{l}\text { Planície de } \\
\text { inundação }\end{array}$ \\
\hline $\begin{array}{c}\text { Textura de material de } \\
\text { leito }\end{array}$ & Arenosa & Rochoso & Leito Arenoso & Arenoso & $\begin{array}{l}\text { Rochoso e } \\
\text { cascalhento }\end{array}$ & $\begin{array}{l}\text { Cascalhento e } \\
\text { argiloso }\end{array}$ \\
\hline \multicolumn{7}{|c|}{ Condicionantes fluviais } \\
\hline Bacia à montante & $\begin{array}{l}\text { Áreas altas e } \\
\text { planas }\end{array}$ & $\begin{array}{l}\text { Falhamentos } \\
\text { afloramento } \\
\text { s e declives } \\
\text { acentuados }\end{array}$ & $\begin{array}{l}\text { Falhamentos, } \\
\text { afloramentos e } \\
\text { declives } \\
\text { acentuados }\end{array}$ & $\begin{array}{c}\text { Áreas de } \\
\text { transporte de } \\
\text { sedimentos }\end{array}$ & $\begin{array}{c}\text { Áreas de transporte } \\
\text { de sedimentos }\end{array}$ & $\begin{array}{c}\text { Áreas de } \\
\text { transporte de } \\
\text { sedimentos }\end{array}$ \\
\hline Geologia & Cristalina & Cristalina & Cristalina & $\begin{array}{l}\text { Cristalina e } \\
\text { Sedimentar }\end{array}$ & Sedimentar & Sedimentar \\
\hline Zona Processual & $\begin{array}{l}\text { Erosão e } \\
\text { Transporte }\end{array}$ & $\begin{array}{l}\text { Erosão e } \\
\text { transporte }\end{array}$ & $\begin{array}{l}\text { Erosão e } \\
\text { transporte }\end{array}$ & Deposição & $\begin{array}{l}\text { Transporte e } \\
\text { deposição }\end{array}$ & Deposição \\
\hline Morfometria do vale & $\begin{array}{c}\text { 14m de largura; } \\
\text { 1,3 m de } \\
\text { profundidade }\end{array}$ & $\begin{array}{c}29,9 \mathrm{~m} \mathrm{de} \\
\text { largura; } \\
3,3 \mathrm{~m} \mathrm{de} \\
\text { profundidad } \\
\text { e }\end{array}$ & $\begin{array}{c}9,8 \mathrm{~m} \text { de largura; } \\
2,7 \mathrm{~m} \text { de } \\
\text { profundidade }\end{array}$ & $\begin{array}{c}50 \mathrm{~m} \text { de } \\
\text { largura; } 3,8, \\
\text { de } \\
\text { profundidade }\end{array}$ & $\begin{array}{c}\text { 63,4m de largura; } \\
2,9 \mathrm{~m} \text { de } \\
\text { profundidade }\end{array}$ & $\begin{array}{c}8,5 \mathrm{~m} \text { de largura; } \\
1,5 \mathrm{~m} \text { de } \\
\text { profundidade }\end{array}$ \\
\hline \multicolumn{7}{|c|}{ Anomalias fluviais } \\
\hline $1^{\text {a }}$ ordem & --- & 1 & 1 & 1 & --- & --- \\
\hline $2^{\mathrm{a}}$ ordem & --- & 3 & --- & 3 & 4 & 1 \\
\hline \multicolumn{7}{|c|}{ Stream Power Index } \\
\hline Média $\left(W / m^{2}\right)$ & 1083533 & 623984 & 609118 & 227284 & 56205 & 4310 \\
\hline
\end{tabular}

Fonte: Autoral (2020). 
O alto curso do rio Piranhas apresenta 6 estilos fluviais distintos, onde os estilos confinados e parcialmente confinados estão localizados nas áreas de cabeceira da bacia hidrográfica, com exceção do Estilo Fluvial Parcialmente Confinado Arenoso - EFPCA, localizado na foz da bacia hidrográfica. No entanto, os estilos não confinados possuem maiores extensões se comparados com os confinados e parcialmente confinados, tendo em vista que estão associados a áreas majoritariamente planas, que são maioria na bacia hidrográfica. Dessa maneira, na busca de compreender os parâmetros de controle dos estilos fluviais, foi gerado um mapa de anomalias de inclinação da superfície para o rio Piranhas (Figura 5).

De acordo com a figura 5 pode-se observar que o rio Piranhas apresenta 3 anomalias de $1^{\text {a }}$ Ordem e 11 anomalias de $2^{\text {a }}$ Ordem. De modo geral, as características geológicas na bacia indicam relação intima com as variações topográficas a que os estilos são submetidos, tendo em vista que o rio Piranhas possui apenas seu terço inferior sobre terreno sedimentar. Assim, os estilos fluviais confinados que ocorrem no rio Piranhas estão intimamente associados a limites demarcados por anomalias de $1^{\text {a }}$ Ordem.

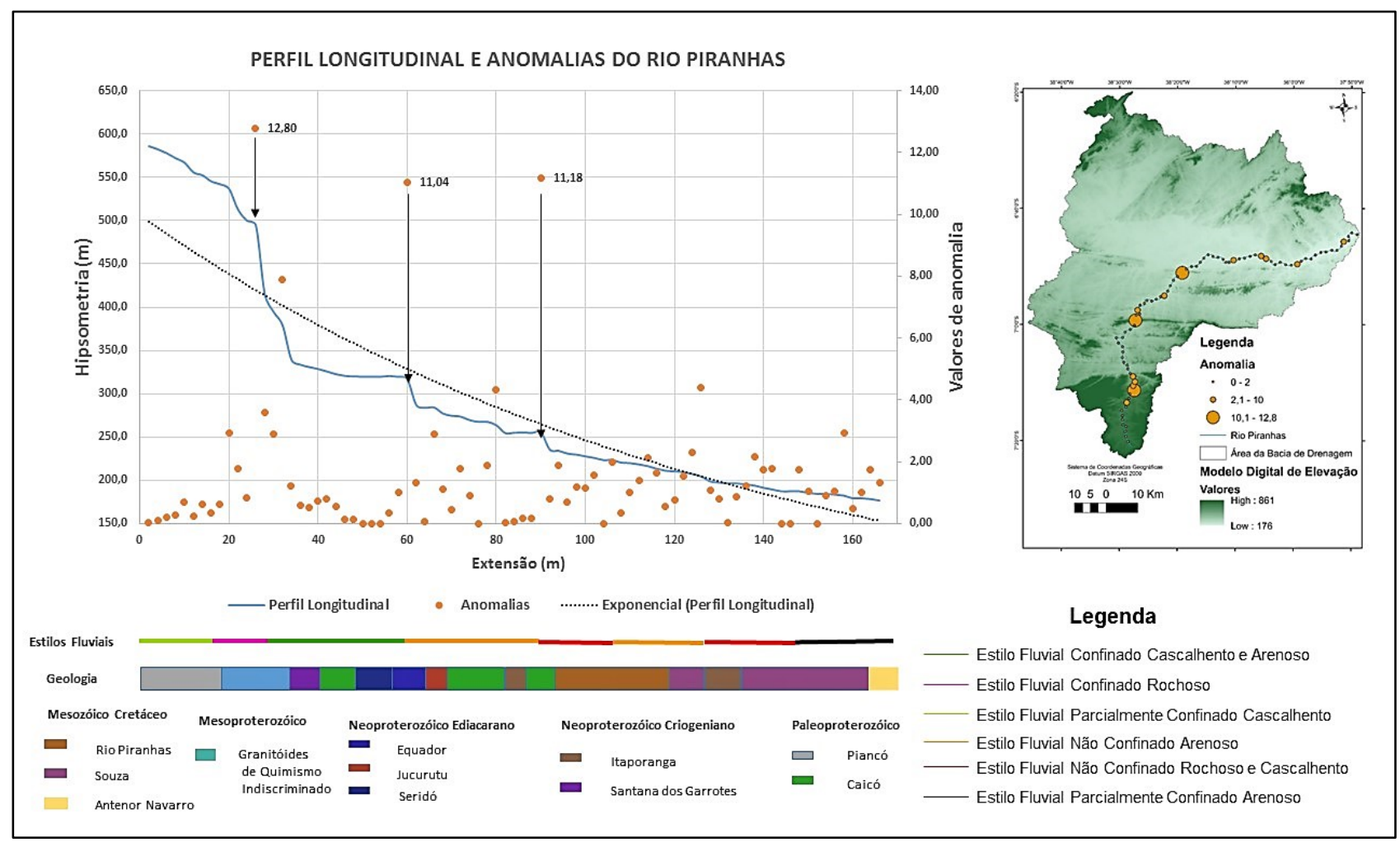

Figura 5 - Relação entre anomalia e estilos fluviais do alto curso do rio Piranhas.

Fonte: Autoral (2020).

Observa-se que os limites dos estilos localizados na cabeceira do rio Piranhas de maneira geral estão associados aos pontos de anomalias de $1^{\text {a }}$ ordem, tendo como exemplo o contato entre o Estilo Fluvial Confiando Cascalhento e Arenoso (EFCCA) com o Estilo Fluvial Confinado Rochoso (EFCR). É fato que de acordo com a Figura 5, não é regra geral que as anomalias sejam 
demarcadoras de todos os estilos fluviais do rio Piranhas, mas apenas dos rios confinados. No entanto, as anomalias agem em sua maioria como condicionantes de processos fluviais atuantes e consequentemente de alguns estilos, pelo fato de estarem inseridas nos limites ou na extensão dos estilos (Figura 6). Desta maneira, o Estilo Fluvial Confinado Rochoso (EFCR) e Confinado Cascalhento e Arenoso (EFCCA) que apresentam processo de erosão e transporte localizados entre duas anomalias de $1^{\circ}$ Ordem e a concentração de anomalias de $2^{\mathrm{a}}$ ordem no Estilo Fluvial Não Confiando Rochoso e Cascalhento (EFNCRC) faz com que ocorra o predomínio de processos de erosão e transporte. Todavia, inicia-se o processo de transporte e deposição no Estilo Fluvial Não Confiando Arenoso (EFNCA) que possui apenas 2 anomalias de $2^{\mathrm{a}}$ ordem, que é $100 \%$ do total de anomalias neste estilo, mas que não são capazes de alterar o processo geomorfológico deposicional.

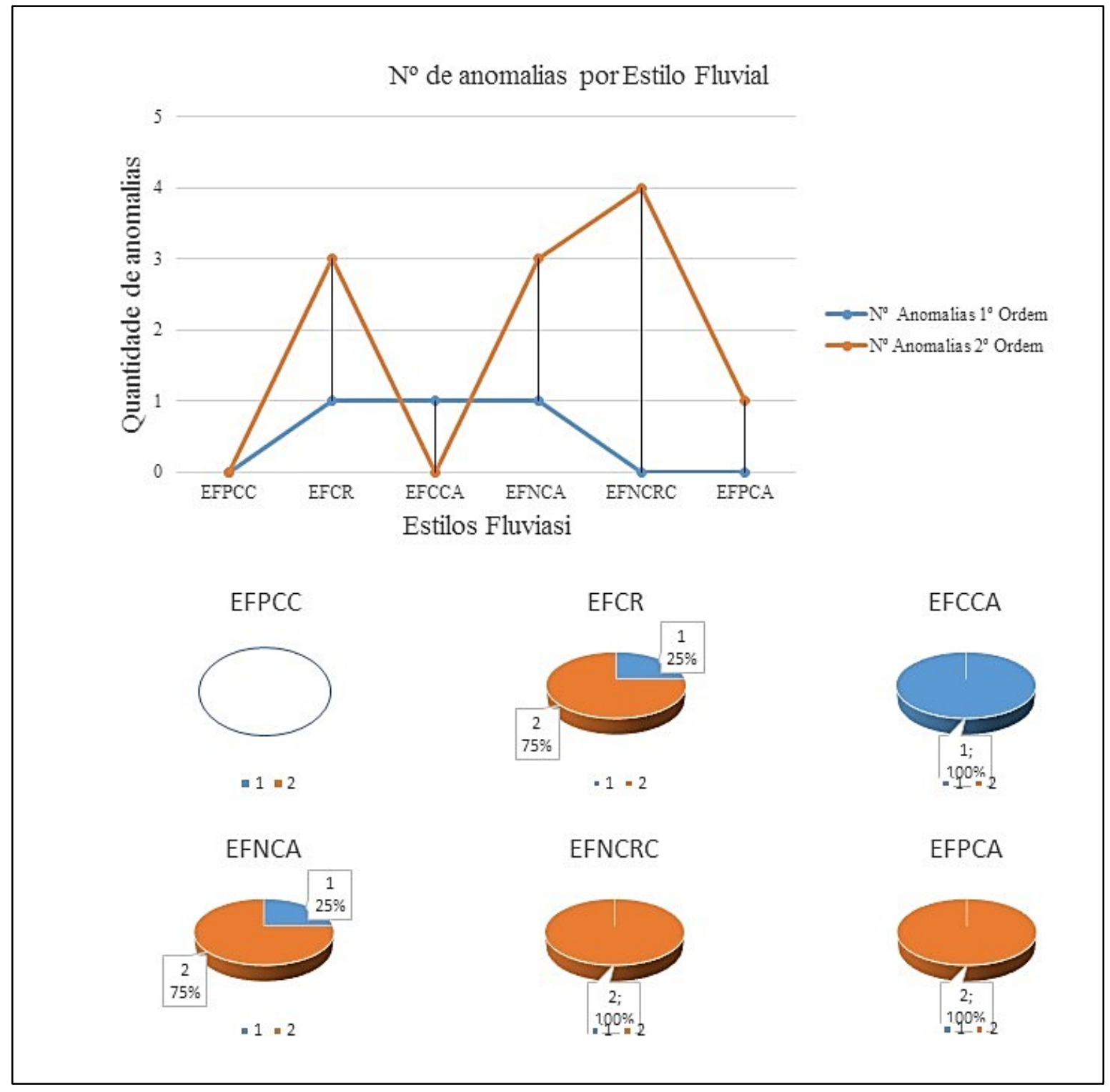

Figura 6 - Quantidade de anomalias por estilo fluvial da bacia do alto curso do rio Piranhas.

Fonte: Autoral (2020). 
O índice de energia de fluxo (Stream Power Index - SPI), é um indicativo de potencial de vazão de energia em determinado trecho de rio em uma bacia hidrográfica (DANIELSON, T. 2013), podendo indicar processo geomorfológico atuante em uma determinada área de captação (WILSON e LORANG, 2000). Assim, o rio Piranhas apresenta os maiores índices de Stream Power nos locais onde ocorrem anomalias de $1^{\text {a }}$ ordem ou entre elas, tendo em vista a disposição mais inclinada da superfície nesses locais próximos à cabeceira de drenagem de substrato cristalino (Figura 7).

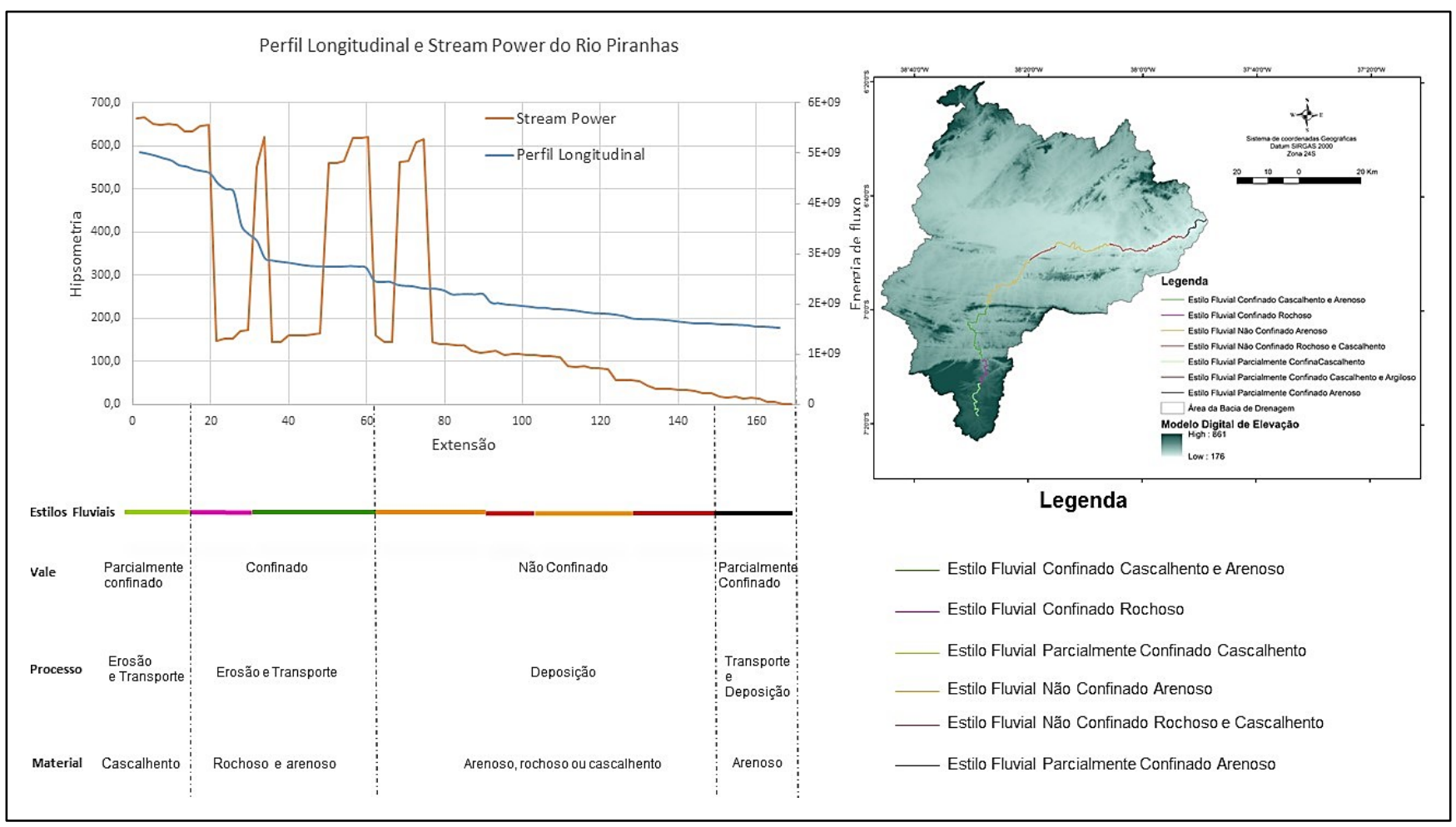

Figura 7 - Relação entre estilos fluviais e energia de fluxo do alto curso do rio Piranhas. Fonte: Autoral (2020).

Os estilos fluviais localizados na cabeceira do rio Piranhas apresentam picos de altos índices de Stream Power principalmente nos estilos confinados e parcialmente confinados. Sendo assim, é no Estilo Fluvial Parcialmente Confinado Cascalhento - EFPCC, Estilo Fluvial Confinado Rochoso - EFCR e Estilo Fluvial Confinado Cascalhento e Arenoso - EFCCA onde ocorrem os maiores índices de energia de fluxo da bacia hidrográfica do alto curso do rio Piranhas. É importante salientar que mesmo ocorrendo um pico de energia de fluxo sobre o Estilo Fluvial Não Confinado Arenoso - EFNCA, o comportamento do estilo continua sendo deposicional, tendo em vista a área majoritariamente plana em que tal estilo escoa. Os controles de estilos causam processos individualizados que corroboram em diferentes dinâmicas fluviais e consequentemente diferentes morfologias entre os estilos fluviais (Figura 8). 


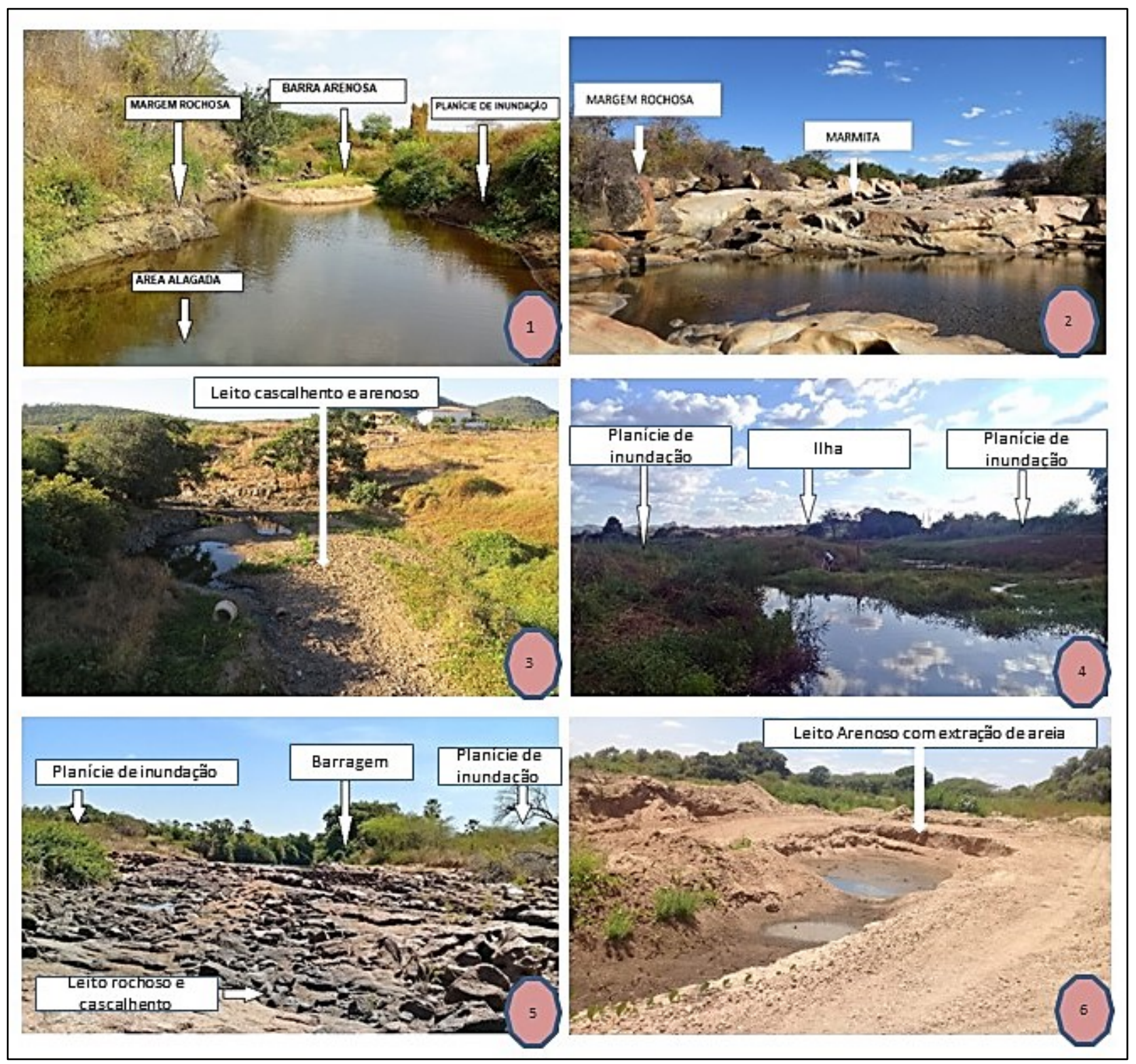

Figura 8 - 1- Estilo Fluvial Parcialmente Confinado Rochoso; 2- Estilo Fluvial Confinado Rochoso; 3 - Estilo Fluvial Confinado Rochoso o e cascalhento; 4 - Estilo Não confinado arenoso; 5 - Estilo Não confinado Rochoso e Cascalhento; 6 - Estilo Parcialmente Confinado Arenoso.

Fonte: Autoral (2020).

As anomalias de inclinação da superfície estão intimamente associadas à energia de fluxo que ocorre na bacia hidrográfica do alto curso do rio Piranhas, onde os estilos fluviais de cabeceira (EFPCC, EFCR e EFCCA) apresentam os maiores valores de energia de fluxo associados a anomalias de $1^{\text {a }}$ Ordem. Os estilos não confinados à jusante apresentam concentração de anomalias de $2^{\text {a }}$ Ordem, principalmente o Estilo Fluvial Não Confinado Rochoso e Cascalhento - EFNCRC, mas que são capazes de gerar alteração no processo geomorfológico atuante em seus alcances se houver concentração de anomalias de $2^{\mathrm{a}}$ Ordem (Figura 6). Assim, o rio Piranhas apresenta anomalias de $1^{\text {a }}$ Ordem que correspondem a demarcadoras de processos de erosão e transporte, tendo em vista as características geológicas cristalinas e variações abruptas de topografia por onde escoam. As anomalias de $2^{\mathrm{a}}$ Ordem só são capazes de gerar alteração nos processos 
geomorfológicos caso haja concentração destas em um mesmo estilo fluvial, como ocorre com o EFNCRC.

\section{CONCLUSÕES}

A metodologia de estilos fluviais permite conhecer o caráter e comportamento fluviais atuais de canais fluviais. Sendo assim, tendo em vista que a metodologia é aplicável a diferentes sistemas morfoclimáticos sem a necessidade de adaptações, permite que as análises sejam mais próximas da realidade sistêmica dos canais fluviais semiáridos. Nesse sentido, a identificação dos controles dos estilos se torna ferramenta fundamental no intuito de compreender como eles condicionam os processos geomorfológicos e fundamentam a dinâmica dos sistemas fluviais semiáridos.

Tais parâmetros de controle dos estilos fluviais vistos como anomalias e stream power index (SPI), são representados por dados estatísticos que ajudam no entendimento dos sistemas fluviais de forma quantitativa, permitindo uma discussão de fácil entendimento e podendo ser usada em qualquer bacia hidrográfica pela sua aplicabilidade.

Este tipo de análise é fundamental para compreender a situação e condicionantes atuais de um sistema fluvial, podendo ser utilizado como base para pesquisas futuras (como é o caso deste estudo), tendo em vista a necessidade de inferir através de modelagem os cenários futuros que um rio pode apresentar, partindo da premissa de que o presente é a chave do passado, e compreender a dinâmica nestes dois tempos, permite modelar o futuro de um rio (BRIERLEY e FRIYRS, 2005).

\section{REFERÊNCIAS}

BRIERLEY, G.; FRYIRS, K. Geomorphology and River Management: applications of the river styles framework. 1. ed. Oxford: Blackwell Publishing, 2005. 412p.

CAMPELO, R. C. Análise de terrenos na porção sententrional da Província Borborema, NE do Brasil: Integração de dados geológicos e gravimétricos. 1999. 140 f. Dissertação (Mestrado em Geofísica) - Centro de Ciências Exatas e da Terra, Universidade Federal do Rio Grande do Norte, Natal, 1999.

CHRISTOFOLETTI, A. Geomorfologia. 1. ed. São Paulo: Edgard Blücher, 1980. 188p.

CHRISTOFOLETTI, A. Geomorfologia fluvial: o canal fluvial. 2. ed. São Paulo: Edgard Blücher, 1981. 313p.

DANIELSON, T. Utilizing a High Resolution Digital Elevation Model (DEM) to Apply Stream Power Index (SPI) to the Gilmore Creek Watershed in Winona County, Minnesota. Papers In Resource Analysis, Winona, v. 15, n. 11, p. 1-11, 2013. 
ETCHEBEHERE, M. L. C. Terraços neoquaternários no vale do Rio do Peixe, Planalto Ocidental Paulista: implicações estratigráficas e tectônicas. 2000. 2645 f. Tese (Doutorado em Geociências) Instituto de Geociências e Ciências Exatas, Universidade Estadual Paulista Júlio de Mesquita Filho, Rio Claro, 2000.

HACK, J. T. Stream-profile analysis and stream-gradient index. Journal of Research of the United States Geological Survey, v. 1, n. 4, p. 421-429, 1973.

LIMA, A. G. Índice de gradiente de canal: significados e diretrizes para aplicação. Brazilian Geographical Journal: Geosciences and Humanities research medium, Uberlândia, v. 4, p. 680$692,2013$.

LIMA, K. C.; LUPINACCI, C. M. Morfologias Fluviais em Ambiente Semiárido: Questões Teóricas Aplicadas a um Estudo de Caso. Revista Brasileira de Geomorfologia, Uberlândia, v. 20, n. 3, p. 475-490, 2019.

MAIA, R. P.; BEZERRA, F. H. R. Neotectônica, Geomorfologia e Sistemas Fluviais: Uma Análise Preliminar do Contexto Nordestino. Revista Brasileira de Geomorfologia, Uberlândia, v. 12, n. 3, p. 37-46, 2010.

MALTCHIK, L. Ecologia de Rios Intermitentes Tropicais. In: POMPÊO, M. L. M. Perspectivas na Limnologia do Brasil. São Paulo: Editora União, 1999. cap. 5, p. 1-11.

POURGHASEMI, H.; PRADHAN, B.; GOKCEOGLU, C.; MOEZZI, K. D. A comparative assessment of prediction capabilities of Dempster-Shafer and Weights-of-evidence models in landslide susceptibility mapping using GIS. Geomatics, Natural Hazards And Risk, v. 4, n. 2, p. 93-118, 1977.

SILVA, R. N.; GOMES, D. D. M.; LIMA, C. E. S.; GOLDFARB, M. C. Uso do índice RDE para determinação de anomalias de drenagem no Rio Capibaribe (PE). Reget, Santa Maria, v. 20, n. 1, p. 552-565, 2016.

SOUZA, J. O. P. Dos Sistemas Ambientais ao Sistema Fluvial - Uma Revisão de Conceitos. Caminhos de Geografia, Uberlândia, v. 14, n. 47, p. 224-233, 2013.

SOUZA, J. O. P.; ALMEIDA, J. Processos Fluviais em Terras Secas. Revista Okara, João Pessoa, v. 9, n. 1, p. 108-122, 2015.

SUTFIN, N. A.; SHAW, J. R.; WOHL, E. E.; COOPER, D. J. A Geomorphic Classification of Ephemeral Channels in a Mountainous, Arid Rerion, Southwestern Arizon. Geomorphology, v. 221, p. 164-175, 2014.

TAGIL, S.; JENNESS, J. GIS-Based Automated Landform Classification and Topographic, Landcover and Geologic Attributes of Landforms Around the Yazoren Polje, Turkey. Journal Of Applied Sciences, v. 6, n. 8, p. 910-921, 2008.

THOMSON, J. R.; TAYLOR, M. P.; BRIERLEY, G. Are River Styles Ecologically Meaningful? A Test of the Ecological Significance of a Geomorphic River Characterization Scheme. Aquatic Conservation-marine And Freshwater Ecosystems, v. 14, n. 1, p. 25-48, 2004. 
WILSON, J. P.; LORANG, M. S. Spatial Models of Soil Erosion and GIS. In: FOTherRInghaM, A. S.; WEGENER, M. Spatial Models and GIS: New Potential and New Models. London: Taylor \& Francis, 2000. cap. 6, p. 83-86.

ZANCOPÉ, M. H. C.; PEREZ FILHO, A.; CARPI JUNIOR, S. Anomalias no Perfil Longitudinal dos Meandros do Rio Mogi Guaçu. Revista Brasileira de Geomorfologia, Uberlândia, v. 10, n. 1, p. 31-42, 2009.

Trabalho enviado em $02 / 02 / 2020$

Trabalho aceito em 12/03/2020 